\title{
SPECTROSCOPIC AND LASER PROPERTIES OF DIFFERENT MATERIALS DOPED WITH $\mathrm{Pr}^{3+}$ IONS
}

\author{
Z. MierczyK, S. KaCzMareK, K. KopczyŃsKi \\ Institute of Optoelectronics, Military University of Technology \\ Kaliski 2, 00-908 Warsaw, Poland \\ Z. Frukacz, I. Pracka and T. Eukasiewicz \\ Institute of Electronic Materials Technology \\ Wólczyńska 133, 01-919 Warsaw, Poland
}

\begin{abstract}
Examined praseodymium doped crystals with 1 at.\% of $\mathrm{Pr}^{3+}$ ions for $\mathrm{Y}_{3} \mathrm{Al}_{5} \mathrm{O}_{12}$ (YAG), SrLaGa $\mathrm{O}_{7}$ (SLGO) hosts and 3 at.\% of $\mathrm{Pr}^{3+}$ ions for YAlO3 (YAP) hosts were produced using Czochralski method. The luminescence for the range of $200 \div 800 \mathrm{~nm}$ and absorption spectra for a wide range of $200 \div 6000 \mathrm{~nm}$, for $\mathrm{Pr}^{3+}: \mathrm{YAG}, \mathrm{Pr}^{3+}:$ SLGO and $\mathrm{Pr}^{3+}$ :YAP crystals have been measured. A free-running laser emission of $\lambda=0.744 \mu \mathrm{m}$ for Pr:YAG and $\lambda=0.729 \mu \mathrm{m}$ for $\operatorname{Pr}:$ SLGO for two different transmissions of output mirrors has been obtained.
\end{abstract}

PACS numbers: 42.70.Hj, 78.20.Dj, 78.55.IIx

\section{Introduction}

Trivalent praseodymium in crystals is a well known ion which has a very rich emission spectrum extending from ultraviolet (UV) to infrared (IR) $[1,2]$. Because of the energy level structure and suitable lifetimes of the excited states, $\mathrm{Pr}^{3+}$ systems are specially attractive as active materials for lasers emitting in a short wavelength range. The $\mathrm{CW}$ stimulated emission at several orange and red wavelengths in $\mathrm{Pr}^{3+}$ doped perovskite (YAP) has been reported in [3]. Simultaneous blue and orange wavelengths lasing in $\mathrm{Pr}^{3+}$ doped YAP and YAG crystals have been observed in [4].

\section{Experimental results}

Samples from $\operatorname{Pr}$ : YAG, Pr:SLGO and Pr:YAP crystals with diameters of $10 \mathrm{~mm}$ and thickness of $1 \div 2 \mathrm{~mm}$, both sides optically polished, were cut out from the most homogeneous parts of the crystals (examined with Mach-Zehnder interferometer system) made in the Institute of Electronic Materials Technology. These samples have undergone spectroscopic and luminescence investigations.

In order to determine the absorption coefficient in dependence on wavelength, the samples transmission was measured using the following spectrophotometers: 
a) LAMBDA-2 of Perkin-Elmer in the spectral range of $200 \div 1100 \mathrm{~nm}$,

b) ACTA VII of Beckman in the spectral range of $1100 \div 1400 \mathrm{~nm}$ and

c) Fourier spectrophotometer FTIR 1725 of Perkin-Elmer in the range of 1.4 to $25 \mu \mathrm{m}$.

Dispersion of the absorption coefficient was calculated from transmission measurements considering multiple reflection inside the samples.

Luminescence investigations were carried out using a Perkin-Elmer LS-5B spectrolluorimeter.

Rods of $3 \mathrm{~mm}$ in diameter and about $40 \mathrm{~mm}$ in length were investigated with reference to their laser features. The above investigations were carried out using plane-parallel laser resonator of length $23 \mathrm{~cm}$, and output mirrors of $26 \%$ and $40 \%$ transmition at $0.73 \mu \mathrm{m}$. The laser head consisted of a single linear xenon flash-lamp of $4 \mathrm{~mm}$ in diameter and a reflector made of gold-covered brass. The duration of flash-lamp pulse was equal to $150 \mu$ s and pump energy was changed from 4 to $40 \mathrm{~J}$.

\subsection{Optical investigations}

The results of spectroscopic investigations are shown in Fig. 1. It can be seen that intensity of absorption lines for $\mathrm{Pr}$ : YAG and Pr:YAP crystals is larger than for $\mathrm{Pr}$ :SLGO ones. These lines are placed in the same region of absorption spectrum. An average optical density is greater for Pr:SLGO crystals. The absorption threshold, for crystals, appears at $300 \mathrm{~nm}$ and lattice absorption is observed above $5500 \mathrm{~mm}$.

The results of luminescence measurements are shown in Fig. 2. It was stated that for $\mathrm{Pr}^{3+}$ :YAG crystals, the strongest peaks of luminescence occur at $488 \mathrm{~nm}$, $501 \mathrm{~nm}, 532 \mathrm{~nm}, 563 \mathrm{~nm}, 619 \mathrm{~nm}, 660 \mathrm{~nm}, 714 \mathrm{~nm}$ and $744 \mathrm{~nm}$. For $\mathrm{Pr}^{3+}$ :SLGO crystals the strongest peaks of luminescence appear at $489 \mathrm{~nm}, 503 \mathrm{~nm}, 534 \mathrm{~nm}$, $562 \mathrm{~nm}, 615 \mathrm{~nm}, 646 \mathrm{~nm}, 654 \mathrm{~nm}, 729 \mathrm{~nm}$. For $\mathrm{Pr}^{3+}$ :YAP crystals the strongest peaks of luminescence appear at $504 \mathrm{~nm}, 535 \mathrm{~nm}, 551 \mathrm{~nm}, 615 \mathrm{~nm}, 623 \mathrm{~nm}, 647 \mathrm{~nm}$, $662 \mathrm{~nm}, 719 \mathrm{~nm}, 747 \mathrm{~mm}$.

Figure 3 presents results of absorption measurements of Pr:YAG crystal (thin sample) after UV excitation with xenon pump lamp -10 pulses of $42.2 \mathrm{~J}$ energy with time interval equal to $15 \mathrm{~s}$ between them. From this figure it results that $\mathrm{Pr}$ : YAG crystal is UV radiation sensitive and that there are unstable colour centres after UV radiation. Time quenching interval for transmission of these centres is equal to $1 \% / 1000 \mathrm{~s}$.

\subsection{Lasing invesligations}

A free-ruming laser emission of $\lambda=0.744 \mu \mathrm{m}$ for $\operatorname{Pr}: Y A G$ and $\lambda=0.729 \mu \mathrm{m}$ for Pr : SLGO for two different transmissions of output mirrors has been obtained.

The emitted laser radiation energy was measured by means of Universal Radiometer Rm6600 of Laser Precision Co. with RJP-735 probe. Simultaneously, the lamp pulses were observed on the Tektronix oscilloscope using a high-sensitivity Si photodetector. UV radiation was eliminated by using sodium glass filters inside laser cavity. The results of lasing measurements can be seen in Fig. 4. Thresholds 

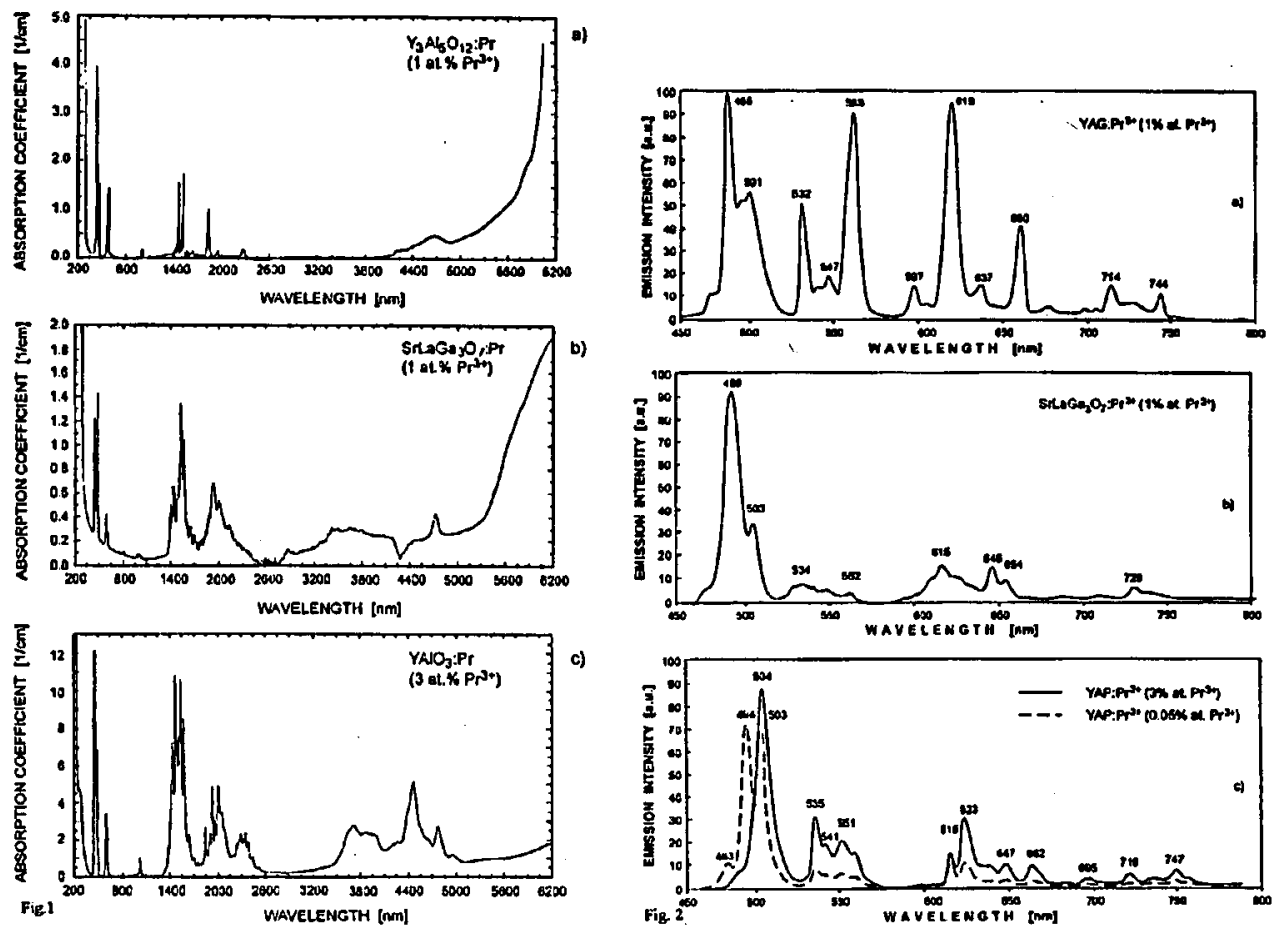

Fig. 1. Absorption coefficient of $\mathrm{Y}_{3} \mathrm{Al}_{5} \mathrm{O}_{12}: \mathrm{Pr}^{3+}$ (a), $\mathrm{SrLaGa}_{3} \mathrm{O}_{7}: \mathrm{Pr}^{3+}$ (b) and $\mathrm{YAlO}_{3}: \mathrm{Pr}^{3+}$ (c) for a wavelength range of 200-6200 $\mathrm{nm}$ at room temperature.

Fig. 2. Emission spectra of YAG: Pr (a), SLGO:Pr (b) and YAP:Pr (c) at room temperature.


Fig. 3. Additional absorption bands of Pr: YAG after excitation with UV.

Fig. 4. Free-ruming emission for SLGO : Pr and YAG: Pr with two different transmission values of output mirrors: $26 \%$ and $40 \%$.

of laser emission for $\mathrm{Pr}^{3+}$ : YAG crystals were smaller than for $\mathrm{Pr}^{3+}$ :SLGO ones (10 $\mathrm{J}$ and $20 \mathrm{~J}$, respectively). Efficiencies of these lasers were $0.24 \%$ and $0.2 \%$, respectively. 
For both types of crystals and for some greater pump energies, the saturation of laser emission was noticed. In the case of $\mathrm{Pr}^{3+}$ : SLGO crystal there were observed coloured centres generated by illuminating the rod with xenon flash-lamp. To avoid the parasite heating of the laser rod and variations of its laser characteristics, the cut-off filters made of sodium glass (cut-off wavelength equal to $350 \mathrm{~nm}$ ) were used.

\section{Resume}

Examined praseodymium doped crystals with 1 at.\% of $\mathrm{Pr}^{3+}$ ions for $\mathrm{Y}_{3} \mathrm{Al}_{5} \mathrm{O}_{12}, \mathrm{SrLaGa}_{3} \mathrm{O}_{7}$ hosts and 3 at.\% of $\mathrm{Pr}^{3+}$ ions for $\mathrm{YAlO}_{3}$ hosts were produced using Czochralski method. The luminescence for the range of $200 \div 800 \mathrm{~nm}$ and absorption spectra for a wide range of $200 \div 6000 \mathrm{~nm}$, for $\mathrm{Pr}^{3+}: \mathrm{YAG}, \mathrm{Pr}^{3+}$ : SLGO and $\mathrm{Pr}^{3+}$ : YAP crystals have been measured. It was stated that for praseodymium doped YAG, YAP and SLGO crystals, the strongest peaks of luminescence occur at about $0.488,0.620$ and $0.730 \mu \mathrm{m}$ and the strongest peaks of absorption occur at $0.44 \div 0.5 \mu \mathrm{m}$ and $0.58 \div 0.62 \mu \mathrm{m}$ bands.

A free-running laser emission of $\lambda=0.744 \mu \mathrm{m}$ for $\mathrm{Pr}: \mathrm{YAG}$ and $\lambda=0.729 \mu \mathrm{m}$ for $\operatorname{Pr}$ : SLGO for two different transmissions of output mirrors has been obtained. Thresholds of laser emission for $\mathrm{Pr}^{3+}$ : YAG crystals were smaller than for $\mathrm{Pr}^{3+}$ : SLGO ones (10 J and $20 \mathrm{~J}$, respectively). Efficiencies of these lasers were $0.24 \%$ and $0.2 \%$, respectively. For both types of crystals and for some greater pump energies, the saturation of laser emission was noticed. In the case of $\mathrm{Pr}^{3+}$ :SLGO crystal there were observed coloured centres generated by illuminating the rod with xenon flash-lamp.

\section{References}

[1] A.A. Kaminskii, Laser Crystals, their Physics and Properties, Springer-Verlag, Berlin 1981.

[2] E.G. Gumanskaya, M.V. Korzlik, S.A. Smirova, V.B. Pavlenko, A.A. Fedorov, Opt. Spectrosc. 72, 86 (1982).

[3] A. Bleckmam, F. Ileine, J.P. Meyn, K. Peterman, G. Ifuber, in: OSA Proceedings on Advanced Solid-State Lasers, Eds. A.A. Pinto, T. Yee Fan, Vol. 15, Optical Society of America, Washington (DC) 1993, p. 199.

[4] M. Malinowski, M.F. Joubert, R. Malion, B. Jacquier, J. Phys. IV Colloq. C4 4, 541 (1994). 